\title{
Perception of Nurse-Midwives on Factors Influencing Oral Contraceptives Use, Misuse, Nonuse and Discontinuation among Clients in Ibadan, Nigeria
}

\author{
Oluwafemi E. Kale ${ }^{1,2^{*}}$, Gbonjubola O. Owolabi ${ }^{1,3}$, Oluwayemisi E. Ekor ${ }^{4}$, \\ Abimbola O. Oluwatosin ${ }^{3}$, Medinat T. Adeniran ${ }^{1}$, Oluwafemi A. Ajose ${ }^{4}$ \\ ${ }^{1}$.(Department of Pharmacology, Oyo State School of Nursing, Ibadan Oyo State, Nigeria) ${ }^{2}$ (Department of \\ Pharmacology, Olabisi Onabanjo University, Ago-Iwoye, Ogun State, Nigeria. ${ }^{3 .}$ (Department of Nursing, \\ University of Ibadan, Oyo State, Nigeria). ${ }^{4}$ (Department of Clinical Sciences, Olabisi Onabanjo University, \\ Ago-Iwoye, Ogun State School, Nigeria).
}

\begin{abstract}
The present study assessed perception of nurse-midwives (NMs) on factors influencing oral contraceptives (OC) use, misuse, nonuse and discontinuation among clients in Ibadan Nigeria. Thus, to ascertain possible factors that influences the application of OC among users in order to improve measurement quality as well as attract clinical importance. A qualitative randomized survey data from interviewer administered structured-based questionnaires and in-depth interviews were conducted. One hundred and fifty

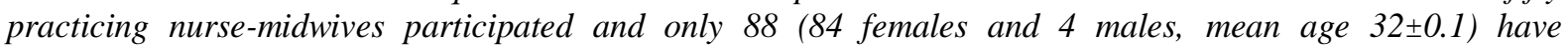
experience with clients on OC. From Our results, $10.2 \%$ were registered nurses $(R N), 64.8 \%$ were midwives (RN/RM), 20.5\% bachelors (RN/RM/BNSC) while 3.3\% had masters and doctorate respectively. $64.8 \%$ of NMs disclosed that clients got pregnant because of inadequate knowledge of differences in medications while $84.1 \%$ NMs emphasized on forgetfulness. $76.1 \%$ of NMs associated high risks of side effects to switching pills. NMs associated unwanted pregnancy and adverse drug effects to ineffective use, misuse and discontinuation respectively. Significant association $(C I=95 \%=0.000-0.064 ; d f=4)$ existed between NMs perception and factors influencing OC application. According to the NMs, those who do not use OC and or users who misused or discontinued the method were dissatisfied either directly or indirectly.
\end{abstract}

Key words: Oral Contraceptives, Nurse-Midwives Perception, Use, Nonuse, Discontinuation.

\section{Introduction}

The use of modern contraceptives as one dimension of fertility change has been studied extensively. Also, the safety of oral contraceptives (OC) has been documented and is well established ${ }^{1}$. However, in the recent, an alternate means of achieving effective and safe contraception in order to ensure optimal choices and options available have arouse the interest of clinical scientists. Current worldwide estimates are that one-fifth of pregnancies are terminated annually by abortion ${ }^{2}$ and $62 \%$ of married women use a contraceptive method ${ }^{3}$.

In 2008, the Nigeria Demographic and Health Survey (NDHS) found that only 10\% of married women of reproductive age use contraceptives and that unintended pregnancies is the result of contraceptive method failure, misuse or discontinuation ${ }^{4}$. In addition, data from the National Survey of Family Growth indicate that typical users report a $9 \%$ failure rate ${ }^{3}$ due to pill-taking mistakes. This further supports the indication that the benefits accompanying their use outweigh the medical risks ${ }^{5}$ via fertility reduction ${ }^{6}$. Evidence abound that women who misuse or discontinue $\mathrm{OC}$ are three times as likely to have an unintended pregnancy as those who continue the method ${ }^{4}$. Although, the strong negative socio-cultural perception in our environment remains inevitable, the major concerns have been raised over the notable complications and diseases associated with long term safety of these agents. Because there appear no best methods for measuring OC use that are accepted as standard ${ }^{7,9,910,11}$, the majority of OC investigations have relied on interviews and questionnaires. Self report may remain the most common oral contraceptive use measure of convenience, ease of administration, and noninvasiveness ${ }^{8}$, yet, it is the least rigorous way to assess contraceptive behavior, given the strong potential for reporting bias ${ }^{12,13}$. This is not without the likelihood of social desirability bias among populations ${ }^{13}$. It is pertinent to stress that inconsistent use of the terms compliance, adherence, continuation, and pill-taking behavior have contributed to conflicting and equivocal findings in contraceptive research ${ }^{17}$. Even though a considerable body of work on OC use patterns exists, users and sometimes nonusers rarely use consistent terminology appropriately and might have often used them interchangeably ${ }^{7,18}$. In this respect, an intervention of experts solely for clarification of terminology in relation to the users would describe suboptimal and optimal pills use, misuse or discontinuation or even pave ways, and thus improve measurement quality. Such terms as misuse and noncompliance may place blame on the research participant and even expert and fail to account for those who may have every intention of complying, but may not understand how to use it correctly or may not 
have continuous access. In addition, agreeing on durable terms and standardized applications of them will increase reliability and validity across studies and improve our ability to synthesize findings and evaluate approaches for measurement ${ }^{14,9}$. Thus, studies to whether nurse-midwives opinions may offer such a guide needed in order to strengthen self-report, the mainstay of contraceptive research ${ }^{15,16,17}$ are available. In Ibadan, the capital city of Oyo state Nigeria, no study has reported nurse-midwives perception on factors influencing OC use, misuse, nonuse and discontinuation. This attempt to aggregate nurse-midwives experiences is expected to provide an impetus in part to reduce women's risk of unintended pregnancy while providing an understanding on the extent and consequences of continuation, misuse, nonuse or discontinuation concerns among health professionals. Therefore, this present study investigated the perception of nurse-midwives on factors influencing oral contraceptives use, misuse, nonuse and discontinuation among clients.

\section{Study Design}

\section{Methodology}

This was a descriptive cross sectional survey that targeted the nurse-midwives of Ibadan, Oyo state, Nigeria. The questionnaire was purposely designed for preliminary investigation. Participants consisted of one hundred and fifty qualified nurse-midwives who have managed users and currently practicing. The participants were randomly selected to including those who have had experience with OC users in Ibadan and those who participated in the $7^{\text {th }}$ Edition of the Mandatory Continuous Professional Development Programme for NurseMidwives in Oyo State. Participants were interviewed and also completed questionnaires. Of this, only eightyfour females and four males NMs admitted and completed the questionnaires.

\section{Questionnaire Development}

This study used a self-administered questionnaire developed by the researchers from reviewed literature. The questionnaire was sectioned into four (4) parts: Section A was on Socio-demographic characteristics, section B was on general review of mechanisms and actions of oral contraceptives uses. C was designed to assess perception of nurse-midwives on the use, misuse, nonuse and discontinuation of OC while section D elicited information about the factors influencing the use, misuse, nonuse and discontinuation of OC.

Each of the research question and hypotheses included in the questionnaire were designed appropriately and provided answers to our objectives.

\section{Inclusion Criteria}

All qualified nurse-midwives working in the labour wards or maternity hospital in the selected units who have managed patients, currently practicing and willing to participate were included in this study.

\section{Ethical Consideration}

Prior to the commencement of the study, approval was obtained from the State Committee of the Mandatory Continuous Professional Development Programme for Nurses and Midwives (MCPDPNM) of Oyo state, Nigeria and the Principal Officers of other visited Hospitals followed by the administration of questionnaires. Informed consent was also obtained from participants prior to commencement of this study.

\section{Statistical Analysis}

Data analysis was carried out using Statistical Package of the Social Sciences Version 16 (SPSS). The analysis gave an outline of the frequency distribution of demographic characteristics of the respondents and some key variables relevant to the study objectives and the research questions. The demographic data were analyzed by using the frequency tables and simple percentages. Chi-square was used to test the hypotheses at $\mathrm{P}<$ 0.05 level of significance.

\section{Socio-Demographic Factors}

\section{Results}

Table 1: From the results obtained in this study, $21.6 \%$ of the nurse-midwives (NMs) occupied the age bracket between 26 to 33 years, $31.8 \%$ were between 34 to 41 years while the most experience category occupied between 42 to 65 years. Of these, $10.2 \%$ were registered nurse (RN), $64.8 \%$ were midwives (RN/RM), $20.5 \%$ bachelors (RN/RM/BNSC), $1.1 \%$ masters (RN/RM/BNSC/MSC), $1.1 \%$ masters (BNSC/MSC) and $1.1 \%$ had doctorate (RN/RM/BNSC/MSC/PhD) in nursing. $88.6 \%$ of the participants were married. Of the tribes, 87.5\% of the participants were Yorubas while $9.1 \%$ were the Igbos. $87.5 \%$ of the NMs were Christians while $10.2 \%$ practice Islam. However, in this study, there were $95.5 \%$ females to $4.5 \%$ males. 


\section{Perception Of Nurse-Midwives On Factors Influencing Contraceptives Use, Misuse, Nonuse And Discontinuation Among Clients}

In Figure 1: almost all NMs (91.0\%) interviewed claimed to understand the mechanisms and actions of OC. $75.0 \%$ NMs declined that all OC were the same. $80.7 \%$ of our respondents agreed that one would see her period if she is on OC but $13.3 \%$ posited that it may not appear as when compared with the normal. Virtually all NMs $(96.6 \%)$ disagreed with the notion that $\mathrm{OC}$ could protect women from sexually transmitted infections.

Table 2: $28.4 \%$ NMs agreed with OC use at any other time or doubling the next dose $(30.7 \%)$ when one missed the time scheduled but $33.0 \%$ insisted that such incident should first be made known to a nurse or the clinician. Also, $59.1 \% \mathrm{NM}$ stated that there were 10 per $100 \%$ chances of getting pregnant while on OC, $26.1 \%$ claimed this to be 1 per $100 \%$ while $4.5 \%$ indicated $0.10 \%$ per $100 \%$. NMs $(79.5 \%)$ suggested that users of $\mathrm{OC}$ require clinical experts at any given time.

In Figure 2: 93.2\% NMs indicated that ineffective use or misuse of oral contraceptive could cause unwanted pregnancy. $43.2 \%$ NMs said clients often misuse by rotating the OC with respect to when their partners will be available or some days take all the missed pills at once. $64.8 \%$ of our respondents disclosed that clients got pregnant because they never heard about or known what $\mathrm{OC}$ were and how they work or where they could be obtained. More so, experts (59.1\% NMs) revealed that most clients who are nonusers could be motivated by fear of side effects. While $30.7 \%$ NMs admitted that OC could make clients sick and so many had to stop using them, $20.5 \%$ NMs neither accepted nor rejected the former but $39.8 \%$ declined. $34.1 \%$ NMs said it is not uncommon that fear towards NMs anger in changing methods could disallow clients from further use but 44.4\% did not agreed as observed in our results. 67\% NMs reported their experiences with clients who often in clinic requested the injection in pretence when they suspected that they have become pregnant, perceiving that it would make them abort.

Table 3: 50\% NMs stated that most people taking OC do avoid seeking support from experts. $76.1 \%$ NMs asserted that clients who switch OC possibly may be at high risks of side effects while $85.2 \%$ were positive that menses altered due to $\mathrm{OC}$ would most times normalize itself. $60.2 \% \mathrm{NMs}$ declined that side effects often demand additional doses of OC. $48.9 \%$ NMs said clients most often do not understand the medical professional's advice, although, $40.9 \%$ respondents declined from this while $8.0 \%$ were indifferent. According to our respondents $(84.1 \%$ ), clients often forget to take their pills and $50 \% \mathrm{NMs}$ declined that clients on OC often grieve psychologically. $54.4 \%$ NMs said most people taking OC might do so at someone's knowledge different from health professionals while $72.7 \%$ inferred positively that most clients neither inform their partners nor guidance. $52.3 \%$ of our respondents however reiterated that nurses approach to dealing with side effects often dissatisfy clients. 75\% NMs expressed that failure of nurses to respond to their clients concerns may lead to them stopping their drugs. NMs $(60.2 \%)$ inferred that side effects do not demand additional doses of OC. However, it was suggested that most NMs $(80.7 \% ; \mathrm{p}<0.001-0.06)$ could assist in prescription to regulate menstrual problems.

In Figure 3: NMs ascribed sudden default of clients from OC to lack of attitude to education (50\%), distance of the clinic from their homes $(64.8 \%)$, unreliability of mobile service $(50.0 \%)$, perception that clinic queue were too long $(55.7 \%)$ or better still some clients actively wanted to become pregnant $(62.7 \%)$. NMs (53.4\%) however, opposed the opinion of male rejection of the methods that it makes them sick. Chi-squares analyses showed significant association $(\mathrm{CI}=95 \%=0.000-0.064 ; \mathrm{df}=4)$ between NMs perception and factors influencing OC application.

\section{Discussion}

Evidence abounds that women who misuse or discontinue oral contraceptive (OC) are three times as likely to have an unintended pregnancy as those who continue the method ${ }^{4}$. We evaluated the perception of nurse-midwives (NMs) on the factors influencing OC use, misuse, nonuse and discontinuation among clients in order to aggregate nurse-midwives experiences on clients while providing an understanding on the concerns among health professionals. Since there appear no best methods for measuring oral contraceptives use that are accepted as standard ${ }^{7,8,9,10,11}$, majority of OC investigations have relied on interviews and questionnaires. From our results, the NMs maintained the fact that OC may not necessarily be similar in their mechanisms and actions. And that most women got pregnant because they never heard about or known what OC were, how they work or where they could be obtained. NMs however were of the opinion that a client who missed her pills could use it any other time by doubling the next dose but not without the consent of the prescribers. NMs stressed that one out of ten women has possibility of getting pregnant when the conditions surrounding the drug is not duly followed. More so, in an attempt to best manage OC, clinical experts were adjudged the best. In most times, clients often do not understand the medical professional's advice but maintained that this may often not necessarily make clients on OC grieve psychologically. NMs concluded that side effects do not demand additional doses of OC. This may warrants other health professional opinions and may vary among users. It was however suggested that failure of NMs to respond to their clients concerns may lead to them stopping the pills. 
For example, in two different studies, it was reported that women's options for contraception are often limited by misperceptions of risks by both health care providers and patients ${ }^{19,20}$. And that providers lack of knowledge and discomfort counseling about contraceptive options may place women at greater risk for unplanned, higher risk pregnancies ${ }^{21}$. NMs claimed that clients most often forget to take their pills and switching OC may in part alter the body homeostasis. Though, switching OC methods is a common phenomenon, previous studies found that up to $80 \%$ of women who discontinue or switch, do so to less effective methods ${ }^{24,25}$. Recently, in other countries, women with some medical problems claimed to have received less or inappropriate counseling, placing them at increased risk for unintended pregnancy ${ }^{19,20}$. This further explains why often time users may rely on less effective barrier methods or use no contraceptive method at all which may in chance increase their risk of unintended and undesired pregnancy. There are available evidences that when used properly, OC certainly can plummet pregnancy risk from a specific sex act but users retain their right to this medication in order to realize this important benefit ${ }^{20,21,24}$. From the NMs points of view, an altered menses due to OC would most times normalize itself, although, this may be in part due to humoral feedback mechanism. But, nonuse, ineffective use or misuse of OC could cause unwanted pregnancy. As observed in this study, clients most times often rotate taking the OC with respect to when their partners will be available or some days take all the missed pills at once. In our study, NMs disclosed that clients often in clinic logically may request other methods in pretence when they suspected they were pregnant perceiving that it would make them abort. Most people who were nonusers was said to have linked them to fear of adverse drug reactions. Side effects have often been cited as the major reason for discontinuation of $\mathrm{OC}^{22,25}$. Westhoff and colleagues ${ }^{26}$ also reported that women from publicly funded clinics experienced difficulties in accessing or using methods correctly as a significant barrier to continuation. Davidson and Helzlsouer ${ }^{27}$ maintained a shift in focus on possible adverse effects of OC use due to the identification of a comprehensively beneficial OC that would reduce the risk of breast, ovarian and uterine cancers without other complications. More so, the claim that OC could make clients sick and so many had to stop using them was disapproved, although, insignificantly as observed in this study. Instead, results showed that NMs's anger or occasional unreliable mobile service may disallow many clients from further use or change methods. Similarly, Nelson et al. ${ }^{28}$ obtained that difficulty in obtaining contraception was significantly associated with discontinuation and may reflect difficulty with transportation, uncertain living conditions, and work schedules. Perceptions that clinic queues were too long or the distance of the clinic from their homes supported previous reports ${ }^{19,20,23}$. Some clients actively wanted to become pregnant due to lack of attitude to education. Furthermore, NMs indicated that OC may alter menstruation, but, will not completely abrupt it. Also, our respondents opted out significantly $(\mathrm{p}<0.001)$ that $\mathrm{OC}$ could protect one from sexually transmitted infections. However, Rosenberg et al. ${ }^{25}$ suggested that establishing the truth to women about experience side effects, with vivid orientation of its scale such as ranging from mild or transient to severe, may fascinate accessibility and reliability. Also, with open discussion about what steps to follow if discontented with a method could also recline the risks of discontinuation. Therefore, a proper description of prescription and follow up of OC method would bring about sustainability as well as correct use of these agents.

\section{Conclusion}

Overall, this study reveals some reasons for use, misuses, nonuse as well as discontinuation of OC among users in Ibadan. Although, we did not directly target the users because of the many observations hitherto reported. However, NMs opinions have also established similarly that those women who discontinued their method were dissatisfied either directly or indirectly. Hence, the calls for guidelines, that will regulate OC use, empower NMs and even clients to enhance reliability and quality in these women.

\section{Acknowledgment}

The support of the state committee of the Mandatory Continues Professional Development Programme for Nurse- Midwives (MCPDPNW) ( $7^{\text {th }}$ Edition) of Ibadan Oyo State, Nigeria, is gratefully acknowledged.

\section{Reference}

[1]. J. Trussell and E.G. Raymond . Emergency contraception: a last chance to prevent unintended pregnancy. Office of Population Research, Princeton University. Available at: http://ec.princeton.edu/questions/ec-review.pdf. Retrieved December 3, 2009.

[2]. World Health Organization and Guttmacher Institute. Facts on Induced Abortion: Worldwide Incidence and Trends. October 2008.

[3]. Population Reference Bureau, World Population Data Sheet: 2010, Washington D.C., 2010.

[4]. United Nation Population Fund. UNFPA, Nigeria Country Office Publication.Nigeria Family Planning Analysis, seletected demographic and socio-economic variable, 2010; 2 .

[5]. World Health Organization. Medical eligibility criteria for contraceptive use. Geneva, Switzerland: 2004

[6]. Federal Government of Nigeria. National Policy on Population for Sustainable Development. Policy Document, 2004; 68p.

[7]. S.J. Coons. Medication compliance: The search for answers continues. Clin Ther., 2001; 23:1294-1295.

[8]. L. Osterberg, T. Blaschke. Adherence to medication. N Engl J Med 2005; 353:487-97.

[9]. J.F. Steiner, M. A. Earnest. Lingua Medica: The language of medication-taking. Ann Intern Med 2000; 132:926-930.

[10]. J.W. Brown, A.M. Villarruel, D. Oakley, C. Eribes. Exploring contraceptive pill-taking among Hispanic women in the United States. Health Educ Behav., 2003;30:663-682. 
[11]. L.R. Clark. Will the pill make me sterile? Addressing reproductive health concerns and strategies to improve adherence to hormonal contraceptive regimens in adolescent girls. J Pediatr Adolesc Gynecol., 2001;14:153-162.

[12]. B. Pinter. Continuation and compliance of contraceptive use. Eur J Contracept Reprod Health Care, $2002 ; 7: 178-183$.

[13]. G.S. Stuart, D. A. Grimes. Social desirability bias in family planning studies: A neglected problem. Contraception, 2009; 80:108112 .

[14]. M. Marinker, A. Blenkinsopp, C. Bond, et al. From compliance to concordance: Achieving shared goals in medicine taking. London, UK: Royal Pharmaceutical Society of Great Britain, 1994.

[15]. G. Barrett, and R. Harper, R Health professionals' attitudes to the deregulation of emergency contraception (or the problem of female sexuality). Sociology of Health and Illness, 2000; 22(2), 197-216.

[16]. A.O.Adekunle, A.O. Arowojolu, A.A. Adedimeji, M.A. Okunlola. Emergency contraception: Survey of knowledge, attitudes and practice of health care professionals in Ibadan, Nigeria. Journal of Obstetrics and Gynaecology, 2000; 20(3):284-9.

[17]. G. Aneblom, C.S. Lundborg, A. Carlsten, K. Eurenius, T. Tydén. Emergency contraceptive pills over-the-counter: Practices and attitudes of pharmacy and nurse-midwife providers. Patient Education and Counseling, 2004; 55(1): 129-35.

[18]. F. Coeytaux, E.S Wells, E. Westley. Emergency contraception: have we come full circle? Contraception, $2009 ;$ 80(1):1-3.

[19]. H. R. Murphy, R. C. Temple, V.E Ball, J.M Roland, S. Steel, R. Zill-E-Huma, D. Simmons, L. R.Royce. T.C. Skinner, and on behalf of the East Angila Study Group for Improving Pregnancy Outcomes in Women with Diabetes (EASIPOD). Personal experiences of women with diabetes who do not attend pre-pregnancy care. Diabet Med 2010;27:92-00.

[20]. M. Kaemmerer, M. Vigl, V. Seifert-Klauss, et al. Counseling reproductive health issues in women with congenital heart disease. Clin Res Cardil 2012 [Epub ahead of print].

[21]. M. Dragoman , A. Davis, E. Banks. Contraceptive options for women with preexisting medical conditions. J Wom Health 2010;19:575-80.

[22]. L.R.B Huber, C.J Hogue, A.D Stein, C. Drews, M. Zieman, J. King, et al. Contraceptive use and discontinuation: findings from the contraceptive history, initiation, and choice study. Am J Obstet Gynecol, 2006; 194:1290-5.

[23]. J.J. Frost, S. Singh, L. B. Fine. U.S. women's one-year contraceptive use patterns, 2004. Perspect Sex Reprod Health 2007;39: 4855.

[24]. D.F.Archer. Reversible contraception for women over 35 years of age. Current opinion in Obstetric and Gynaecology, 2002; 4 (6): 891-6

[25]. M.J. Rosenberg, M.S. Burnhill, M.S. Waugh, D.A Grimes, P.J.A. Hillard. Compliance and oral contraceptives: A review. Contraception, 1995; 52:137-141.

[26]. C.L. Westhoff, S. Heartwell, S. Edwards, M. Zieman, G. Stuart, C. Cwiak, et al. Oral contraceptive discontinuation: do side effects matter? Am J Obstet Gynecol 2007 ;196:412.e1-6.

[27]. N.E. Davidson, K. J. Helzlsouer. Good news about oral contraceptives (editorial). N Engl J Med 2002;346:2078-9.

[28]. A. L. Nelson, D. Pietersz, L. E. Nelson, L. Aguilera . Documented short-term continuation rates for combined hormonal contraceptives in an indigent population with ready access to contraceptive supplies. Am J Obstet Gynecol 2007; 196:599.e1-5.

\section{Tables And Figures}

Table 1: Socio-demographic factors of nurse-midwives (NMs) in Ibadan Nigeria.

\begin{tabular}{|c|c|c|}
\hline \multicolumn{2}{|l|}{ Characteristics } & \multirow{2}{*}{$\frac{f(\%)(n=88)}{3(3.4)}$} \\
\hline Age & $18-25$ & \\
\hline & $26-33$ & $19(21.6)$ \\
\hline & $34-41$ & $28(31.8)$ \\
\hline & $42-65$ & $38(43.2)$ \\
\hline & MeantSEM & $31.5 \pm 0.1$ \\
\hline \multirow[t]{2}{*}{ Sex } & Female & $84(95.5)$ \\
\hline & Male & $4(4.5)$ \\
\hline \multirow[t]{3}{*}{ Marital status ${ }^{a}$} & single & $8(9.1)$ \\
\hline & married & $78(88.6)$ \\
\hline & missing & $2(2.3)$ \\
\hline \multirow[t]{2}{*}{ Religion $^{\mathrm{a}}$} & Christianity & $77(87.5)$ \\
\hline & Islam & $9(10.2)$ \\
\hline \multirow[t]{2}{*}{ Ethnic Group ${ }^{b}$} & Yoruba & $77(87.5)$ \\
\hline & Igbo & $8(9.1)$ \\
\hline \multirow[t]{6}{*}{ Edycation ${ }^{c}$} & $\mathrm{RN}$ & $9(10.2)$ \\
\hline & $\mathrm{RN} / \mathrm{RM}$ & $57(64.8)$ \\
\hline & $\mathrm{RN} / \mathrm{RM} / \mathrm{BNSC}$ & $18(20.5)$ \\
\hline & $\mathrm{RN} / \mathrm{RM} / \mathrm{BNSC} / \mathrm{MSC}$ & $1(1.1)$ \\
\hline & $\mathrm{MSC}$ & $1(1.1)$ \\
\hline & $\mathrm{PhD}$ & $1(1.1)$ \\
\hline
\end{tabular}

$\mathrm{f}=$ frequency; $\%=$ percentage; missing numbers, $\mathrm{a}=2(2.3) ; \mathrm{b}=3(3.4) ; \mathrm{c}=1(1.1)$

$\mathrm{SEM}=$ Standard error of mean 


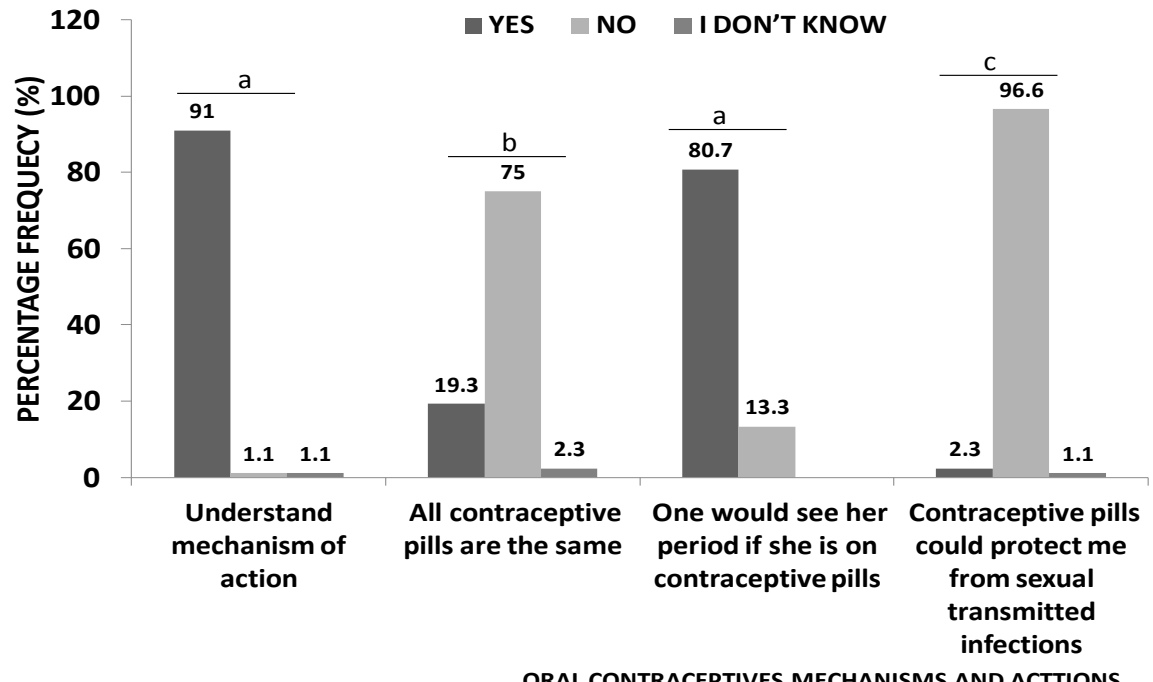

FIGURE 1: showing the results of nurse-midwives perception of oral contraceptives in lbadan Nigeria. $f=$ frequency; $\%$ = percentage; missing numbers, $a=5(5.7) ; b=3(3.4) ; c=1(1.1)$

Table 2: Perception of nurse-midwives on oral contraceptives actions and mechanisms of actions among clients in Ibadan Nigeria.

\begin{tabular}{ll}
\hline Oral Contraceptive & $\mathrm{f}(\%)(\mathrm{n}=88)$ \\
mechanism and actions & \\
\hline What should a client that missed her & \\
contraceptive pills do $0^{\mathrm{a}}$ & \\
Use it any other time & $25(28.4)$ \\
Double the next dose & $27(30.7)$ \\
Complain to a nurse & $29(33.0)$ \\
What are the chances of getting & \\
pregnant while on pills & \\
10 per $100 \%$ & $52(59.1)$ \\
1 per $100 \%$ & $23(26.1)$ \\
0.10 per $100 \%$ & $4(4.5)$
\end{tabular}

Who can best manage contraceptive pills clients $s^{c}$

$\begin{array}{ll}\text { Clinical experts } & 70(79.5) \\ \text { Pharmacy stores } & \text { nil } \\ \text { Parents } & 1(1.1) \\ \text { All the above } & 12(13.6)\end{array}$

$\mathrm{f}=$ frequency; $\%=$ percentage; missing numbers, $\mathrm{a}=7(8.0) ; \mathrm{b}=9(10.2) ; \mathrm{c}=5(5.7)$ 


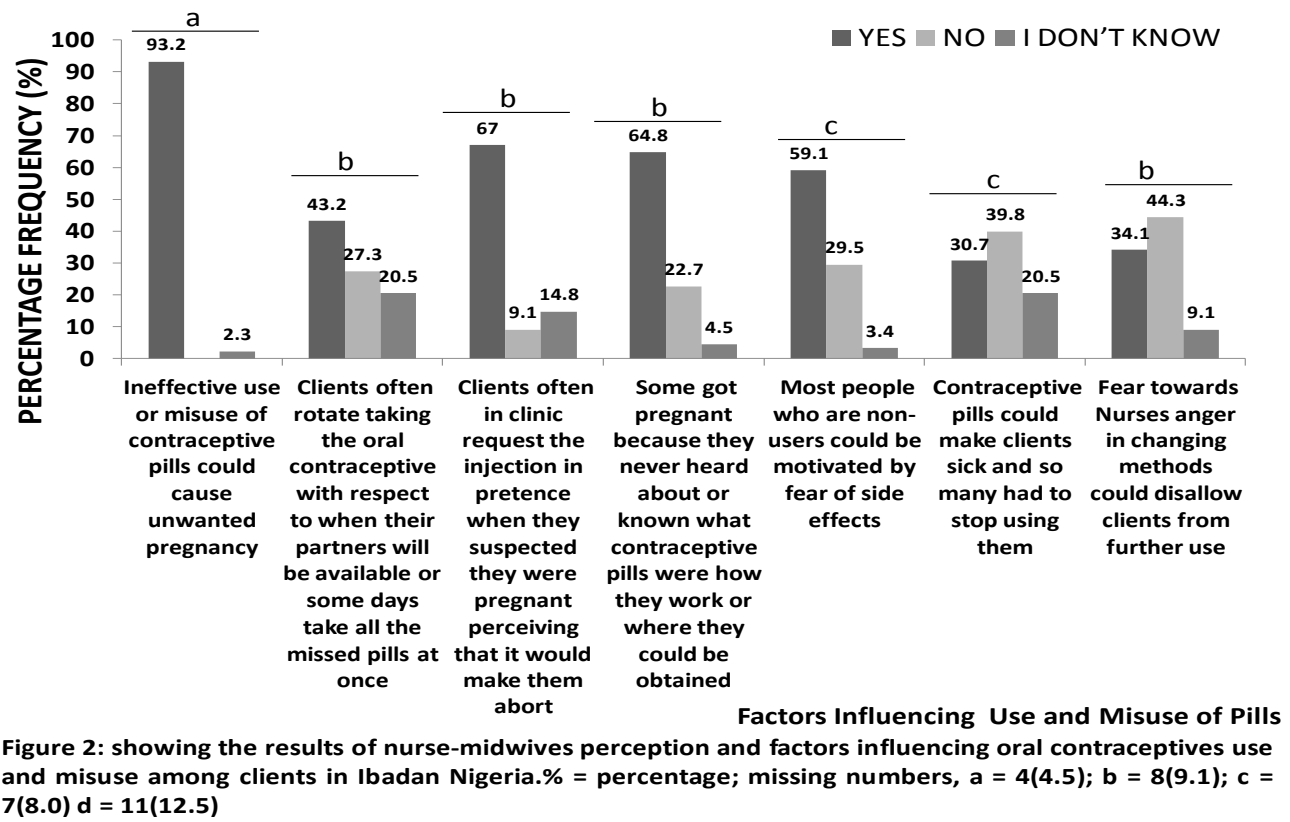

Table 3: Perception of nurse-midwives on use of oral contraceptives use, misuse, nonuse and discontinuation among clients in Ibadan Nigeria.

\begin{tabular}{|c|c|c|c|c|}
\hline \multirow{2}{*}{$\begin{array}{l}\text { Perception on the Use of } \\
\text { Contraceptive Pills }\end{array}$} & \multicolumn{3}{|c|}{$f(\%)(n=88)$} & \multirow[b]{2}{*}{ p-value } \\
\hline & Yes & No & I Don't Know & \\
\hline \multicolumn{5}{|l|}{ Most people taking contraceptive pills } \\
\hline do avoid talking to someone & $25(28.4)$ & $48(54.4)$ & $14(15.9)$ & $0.005-0.03$ \\
\hline \multicolumn{5}{|l|}{ Most people taking contraceptive pills } \\
\hline \multirow{2}{*}{\multicolumn{5}{|c|}{ Clients most often do not understand }} \\
\hline & & & $7(8.0)$ & $0.013-0.01$ \\
\hline \multicolumn{5}{|l|}{ Clients on pills often grieve } \\
\hline psychologicallye & $17(19.3)$ & $44(50.0)$ & $21(23.9)$ & $0.01-0.04$ \\
\hline \multicolumn{5}{|l|}{ Most clients do not inform their } \\
\hline guidance or partmers" & $64(72.7)$ & $11(12.5)$ & $11(12.5)$ & $0.03-0.06$ \\
\hline \multicolumn{5}{|l|}{ Nurses approach to dealing with side } \\
\hline effect often dissatisfy clients ${ }^{e}$ & $46(52.3)$ & $29(33.0)$ & $7(8.0)$ & $0.01-0.03$ \\
\hline \multicolumn{5}{|l|}{ Side effects often demand additional } \\
\hline doses of contraceptive pills ${ }^{d}$ & $13(14.8)$ & $53(60.2)$ & $15(17.0)$ & $0.03-0.10$ \\
\hline \multicolumn{5}{|l|}{ Failure of nurses to respond to their } \\
\hline stopping contraceptive pill $s^{o}$ & $66(75.0)$ & $14(15.9)$ & $6(6.8)$ & $0.003-0.10$ \\
\hline \multicolumn{5}{|l|}{ Most nurses could as sist prescribe to } \\
\hline regulate menstrual problems $s^{b}$ & $71(80.7)$ & $10(11.4)$ & $5(5.7)$ & $0.001-0.06$ \\
\hline $\begin{array}{l}\text { Clients most often forget to take } \\
\text { their pill } s^{a}\end{array}$ & $74(84.1)$ & $3(3.4)$ & $4(4.5)$ & $0.015-0.05$ \\
\hline $\begin{array}{l}\text { Switching pills could completely alter } \\
\text { the body homegstasise. }\end{array}$ & $67(76.1)$ & $7(8.0)$ & $8(9.2)$ & $0.001-0.09$ \\
\hline \multicolumn{5}{|c|}{ An altered menses due to contraceptive pills } \\
\hline would most times normalize itself & $75(85.2)$ & $5(5.7)$ & $3(3.4)$ & $0.01-0.09$ \\
\hline
\end{tabular}

percentage; missing numbers, $a=1(1.1) ; b=2(2.3) ; c=\dot{6}(6.8) d \vec{d}=7(8.0) ; e=5(5.7) . C I=95 \% ; X^{2}=10.5-$ $22.3 ; \mathrm{df}=4$. 


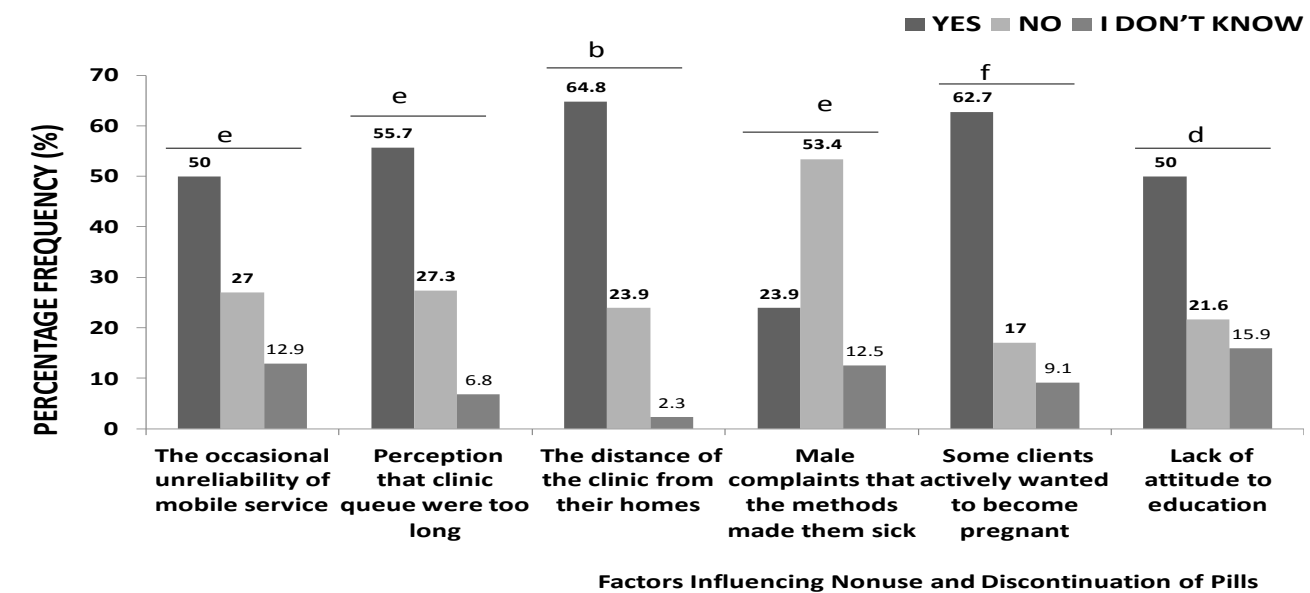

Figure 3: showing the results of nurse-midwives perception and factors influencing oral contraceptives Nonuse and Discontinuation. \% = percentage; missing numbers, $a=4(4.5) ; b=$ 8(9.1); $c=7(8.0) d=11(12.5) ; e=9(10.2) ; f=10(11.4)$. 